\title{
Researchon Impact Resistance of Fibre Reinforced Concrete
}

\author{
K. SaiAbhinav, C.Sreenivasulu, P.Ukesh Praveen, K.Salini
}

\begin{abstract}
: in this exam, an undertaking is needed to bear in mind the impact restriction of fiber bolstered concrete. on this exam, a easy, rational and reasonable drop weight test become finished on fiber invigorated cement as indicated with the resource of ACI board 544. Fibers containing steel, polypropylene, sisal have been used because the invigorating in four unmistakable quantity components, for instance, $0 \%, 0$. five\%,1\%,1.five\%. The results validated that developing the quantity part of fiber prolonged the impact deterrent of sturdy version stood out from customary bond. The outcomes moreover shown that steel fibers are greater dominant at extending the impact test than severa strands.
\end{abstract}

Keywords: About Fibre reinforced concrete, Steel, Polypropylene, Sisal, Drop weight test, Impact energy.

\section{INTRODUCTION}

Concrete is the most for the maximum element used development fabric in this world. commonly concrete has low flexibility and impact resistance on augmentation decks, Aircrafts, and so forth., for this reason steel, polypropylene, sisal strands are included with sturdy blend. due to an extending use of FRC (fiber-strengthened bond) being advanced like framework decks and army businesses against effect stacks, this robust has noteworthy career in human lifestyles. including strands to strong grows its pliability, unbending nature, flexural nice and obstacle towards dynamic and impact loads. so far now metallic and polypropylene are used being advanced industry. gift research, sisal fiber, metallic and polypropylene fibers are delivered to the strong. the brink volume (L/d) and extent department (Vf) are crucial fiber parameters in FRC. right while breaks are begun in FRC, the fibers endure the associated weights, when the pile grows the strands will through and massive transmit the excess stresses to the framework. In case these nerves outperform the fiber-matrix bond satisfactory, which as a result is motivated with the aid of fiber residences the smash device may incite strands pullout or unevenly burst of the fibers. As such, fiber invigorated concretes are extra adaptable than diverse bonds.

extraordinary hints are prescribed by way of diverse impact test techniques, for instance, shot impact test, drop weight check and dangerous take a look at and they may be used for the exam of effect obstacle of concrete [1-2]. among these systems the Drop weight test proposed by way of the ACI (American strong status quo) board 544 is the most clean

Revised Manuscript Received on April 12, 2019.

K. SaiAbhinav,Annamacharya Institute of Technology and Sciences,Tirupati, A.P, India. (saiabhinav.sai9@gmail.com)

C.Sreenivasulu,Annamacharya Institute of Technology and Sciences,Tirupati, A.P, India (chitralasreenivas@gmail.com)

P.Ukesh Praveen,Annamacharya Institute of Technology and Sciences,Tirupati, A.P, India (Praveen.neo38@gmail.com)

K.Salini,Annamacharya Institute of Technology and Sciences,Tirupati, A.P, India (snehashalini.38@gmail.com) technique for surveying the effect drawback of Fibre[3]. test outcomes from robust models containing 0 .five $\%$ to $1.5 \%$ of strands confirmed that the impact obstacle of bond prolonged both for beginning ruin and last component distinction and undeniable concrete. Marar et al. [4] exhibited that for FRCs containing zero.5\%,1\%, $1.5 \%$ and a pair of $\%$ trapped quit metal strands with aspect extents of 60, seventy five and 83, the fashions with a higher fiber content material (in all of perspective extents) had a better effect first-class; moreover for models with $2 \%$ fiber substance and point of view extents likeness 60 , seventy five and 83 , the wolfed energies extended via 38, 55 and on numerous occasions, independently. Ramakrishnan et al. [5] uncovered that metallic strands prolonged the impact limitation of FRCs as much as numerous events differentiated and the effect restrict of undeniable concrete. using a drop hammer mechanical collecting, Nataraja et al. [6] investigated the effect nature of metal fiber-invigorated concrete with a angle extent of forty and two exceptional kinds, $30 \mathrm{MPa}$ and 50MPa. The effects showed that the effect nature of most of the models for the precept smash and remaining cut up prolonged as the quantity a part of fibers extended. They discovered that a 0 .five $\%$ fiber substance provoked the impact insurances of the FRC check at the leader break and final split developing three and four (times gradually substantial) than the effects from the obvious concrete solely. The foremost attention of this challenge is to recall the effect limit parameter of fiber sustained bond with blend degree of fibers for M30 assessment concrete and performing otherwise with regards to the standard concrete and with understand the precise measurement of extension of strands to concrete and locating maximum outrageous extents

\section{TEST STUDY}

The take a look at examination become based totally on the impact of various fiber quantities on impact resistance of FRC. blend degree turned into organized using IS 102622009 and IS 456-2000 with imply goal nature of $38.25 \mathrm{MPa}$ (M30) for control mix.

fundamentalportland bond (kind 1) become used in this examination. a coarse aggregate with a most outrageous apparent length of nineteen $\mathrm{mm}$ and a first-class aggregate with a fineness modulus of 3.four were used inside the exam. Polypropylene, sisal and trapped stop steel strands had been used; their geometry and clean shape are confirmed up in Fig. 1,2,three and their homes are recorded in table 1. first rate plasticizer of SP-430 became used to change the usefulness of mixes. 


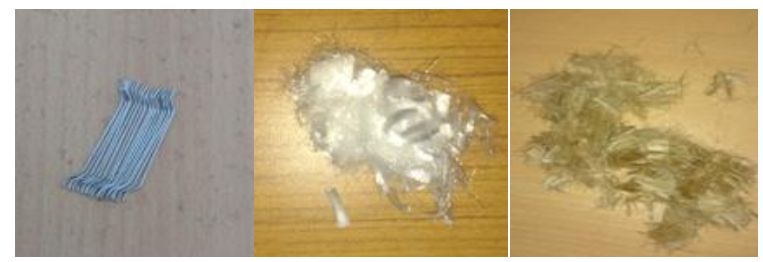

Fig.1.Steel

Fig.2.Polypropylene

Fig.3.Sisal

Table 1: Physical Properties of fibres

\begin{tabular}{lccc}
\hline Fibre & $\begin{array}{c}\text { Diameter } \\
(\mu \mathrm{m})\end{array}$ & $\begin{array}{c}\text { Specific } \\
\text { Gravity }\end{array}$ & $\begin{array}{c}\text { Modulus of } \\
\text { Elasticity }(\mathrm{GPa})\end{array}$ \\
\hline Steel & $5-500$ & 7.84 & 200 \\
Polypropylene & $20-400$ & $0.9-0.95$ & $3.5-10$ \\
Sisal & $10-50$ & 1.5 & -- \\
\hline \hline
\end{tabular}

Squashed shake stones of size $20 \mathrm{~mm}$ and $10 \mathrm{~mm}$ were used as coarse mix and stream sand ended up used as splendid blend. the bigger part express gravity in stove dry condition and water ingestion of the coarse blend $20 \mathrm{~mm}$ and $10 \mathrm{~mm}$ have been 2.58 and 0. three\% exclusively. the larger part careful gravity in stove dry condition and water osmosis of the sand have been 2 .sixty two and $1 \%$ independently.

\section{MIX DESIGN}

On this watch, water bond extent of 0.five become sought after for M30 assessment concrete and metallic, sisal and polypropylene of zero $\%$, zero.5\%, $1 \%$, 1.five $\%$ degree divisions had been used

Table 2: Mix proportions

\begin{tabular}{lc}
\hline \multicolumn{1}{c}{ Constituents } & $\begin{array}{c}\text { Content } \mathrm{kg} / \mathrm{m}^{3} \text { of } \\
\text { concrete }\end{array}$ \\
\hline Cement & 394.32 \\
Fine aggregate & 623.45 \\
Coarse aggregate & 1097.81 \\
Water content & 197.16 \\
Fibres & \\
$0.5 \%$ & 11.56 \\
$1 \%$ & 23.12 \\
$1.5 \%$ & 34.69 \\
Super plasticizer & 9.38 \\
\hline \hline
\end{tabular}

\section{TEST METHOD}

The impact check became finished in accordance with the effect trying out techniques recommended via ACI Committee 544. The test changed into completed by way of dropping a hammer weighing forty four.7N (10 lb) from a stature of $457 \mathrm{~mm}$ (18 inch) extra than as soon as on a $64 \mathrm{~mm}$ (2.five inch) cemented metal ball, that is determined to the most stepped forward motive of the aspect of convergence of the round and empty version (hover) as confirmed up in Fig 4 .

The test continued until frustration. For every version, two traits have been perceived figuring out with starting and outstanding dissatisfactions. The beyond in reality worth gauges the amount of blows required to start a conspicuous destroy, however the very last gauges the quantity of blows required to start and spread components until outrageous frustration. steady with the ACI caution gathering, an authoritative disillusionment takes place at the same time as sufficient effect essentialness has been furnished to unfold the components enough with the purpose that the take a look at model contacts the metal conveys. Regardless, on this exam, if the version disengaged absolutely right right into a balance of before attaining the conveys, by using then this emerge as mentioned the incentive in the lower back of outrageous dissatisfaction. From this take a look at, have an impact on essentialness protection farthest issue of every version became dictated through the circumstanceImpact Energy $(\mathrm{E}$ imp $)=(0.5 \mathrm{mv} 2) \mathrm{n}$

Where $\mathrm{m}=$ mass of the hammer

$$
\begin{aligned}
& \mathrm{n}=\mathrm{no} \text { of blows } \\
& \quad \mathrm{V}=\text { Impact velocity }
\end{aligned}
$$
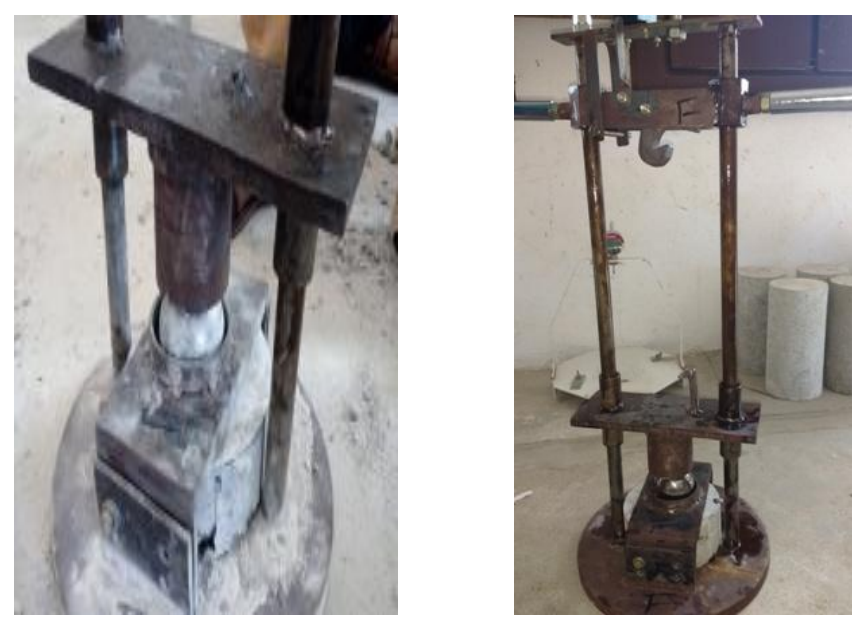

\section{Fig 4 DROPWEIGHT TEST}

\section{RESULTS AND DISCUSSION}

The results are based upon the number of blows that are required to initiate initial crack and number of blows that are required for final crack. Impact resistance of mono fibre reinforced concrete was calculated at different curing periods and compared to conventional concrete. The impact energy was calculated as follows

$$
\begin{aligned}
& \mathrm{H}=(\mathrm{gt} 2) / 2 \\
& \mathrm{~V}=\mathrm{g} * \mathrm{t} \\
& \mathrm{m}=\mathrm{W} / \mathrm{g}
\end{aligned}
$$

where $\mathrm{V}$ is the velocity of hammer by impact $\mathrm{g}$ is acceleration due to gravity, $t$ is the time required for hammer to fall from a height of $457 \mathrm{~mm}, \mathrm{H}$ is the height of the hammer, weight of the hammer substituting the known values in equation 2 we get

$$
\begin{array}{r}
457=(9810 \mathrm{t} 2) / 2 \\
\mathrm{t}=0.3052 \mathrm{sec}
\end{array}
$$

$\mathrm{V}=9810 \times 0.3052=2994.01 \mathrm{~mm} / \mathrm{s}$ 
The above value substitute in Impact energy equation 1 we get

$\mathrm{E} \operatorname{Imp}=(0.5 \times 44.3 \times 2994.012) / 9810$

$=20.345(\mathrm{n}) \mathrm{KN}-\mathrm{mm}$

Table 3: Impact resistance of Steel fibres

\begin{tabular}{llllll}
\hline \hline $\begin{array}{l}\text { Curing } \\
\text { period }\end{array}$ & $\begin{array}{l}\text { Steel } \\
\text { fibredosage } \\
(\%)\end{array}$ & $\begin{array}{l}\text { Initial } \\
\text { crack }\end{array}$ & $\begin{array}{l}\text { Impact } \\
\text { resistance } \\
(\mathrm{KN}-\mathrm{mm})\end{array}$ & $\begin{array}{l}\text { Final } \\
\text { crack }\end{array}$ & $\begin{array}{l}\text { Impact } \\
\text { resistance } \\
(\mathrm{KN}-\mathrm{mm})\end{array}$ \\
\hline \multirow{2}{*}{28 days } & 0.5 & 22 & 447.59 & 30 & 610.35 \\
& 1 & 121 & 2461.74 & 155 & 3153.475 \\
& 1.5 & 168 & 3417.96 & 197 & 4007.965 \\
& 0 & 241 & 4903.145 & 309 & 6286.605 \\
56 days & 0.5 & 135 & 2746.575 & 172 & 3499.34 \\
& 1 & 173 & 3540.03 & 208 & 4231.76 \\
& 1.5 & 253 & 5147.285 & 329 & 6693.505 \\
\hline \hline
\end{tabular}

Table 4: Impact resistance of Polypropylene fibres

\begin{tabular}{llllll}
\hline \hline $\begin{array}{l}\text { Curing } \\
\text { period }\end{array}$ & $\begin{array}{l}\text { Polypropyl } \\
\text { ene } \\
\text { fibredosag } \\
\mathrm{e}(\%)\end{array}$ & $\begin{array}{l}\text { Initial } \\
\text { crack }\end{array}$ & $\begin{array}{l}\text { Impact } \\
\text { resistance } \\
(\mathrm{KN}-\mathrm{mm})\end{array}$ & $\begin{array}{l}\text { Final } \\
\text { crack }\end{array}$ & $\begin{array}{l}\text { Impact } \\
\text { resistance( } \\
\text { KN- m) }\end{array}$ \\
\hline \multirow{2}{*}{28 days } & 0 & 22 & 447.59 & 30 & 610.35 \\
& 0.5 & 41 & 834.145 & 64 & 1302.08 \\
& 1 & 45 & 915.525 & 72 & 1464.84 \\
& 1.5 & 145 & 2950.025 & 192 & 3906.24 \\
& 0 & 25 & 508.625 & 31 & 630.695 \\
56 days & 0.5 & 48 & 976.56 & 74 & 1505.53 \\
& 1 & 54 & 1098.63 & 82 & 1668.29 \\
& 1.5 & 158 & 3214.51 & 205 & 4170.725 \\
\hline \hline
\end{tabular}

Table 5: Impact resistance of Sisal fibres

\begin{tabular}{llllll}
\hline \hline $\begin{array}{l}\text { Curing } \\
\text { period }\end{array}$ & $\begin{array}{l}\text { Sisal fibre } \\
\text { dosage }(\%)\end{array}$ & $\begin{array}{l}\text { Initial } \\
\text { crack }\end{array}$ & $\begin{array}{l}\text { Impact } \\
\text { resistance } \\
(\mathrm{KN}-\mathrm{mm})\end{array}$ & $\begin{array}{l}\text { Final } \\
\text { crack }\end{array}$ & $\begin{array}{l}\text { Impact } \\
\text { resistance } \\
(\mathrm{KN}-\mathrm{mm})\end{array}$ \\
\hline \multirow{6}{*}{28 days } & 0 & 22 & 447.59 & 30 & 610.35 \\
& 0.5 & 39 & 793.455 & 55 & 1118.975 \\
& 1 & 48 & 976.56 & 70 & 1424.15 \\
& 1.5 & 73 & 1485.185 & 96 & 1953.12 \\
& 0 & 25 & 508.625 & 31 & 630.695 \\
56 days & 0.5 & 48 & 976.56 & 64 & 1302.08 \\
& 1 & 61 & 1241.045 & 87 & 1770.015 \\
& 1.5 & 89 & 1810.705 & 102 & 2115.88 \\
\hline \hline
\end{tabular}

\section{8 days curing}
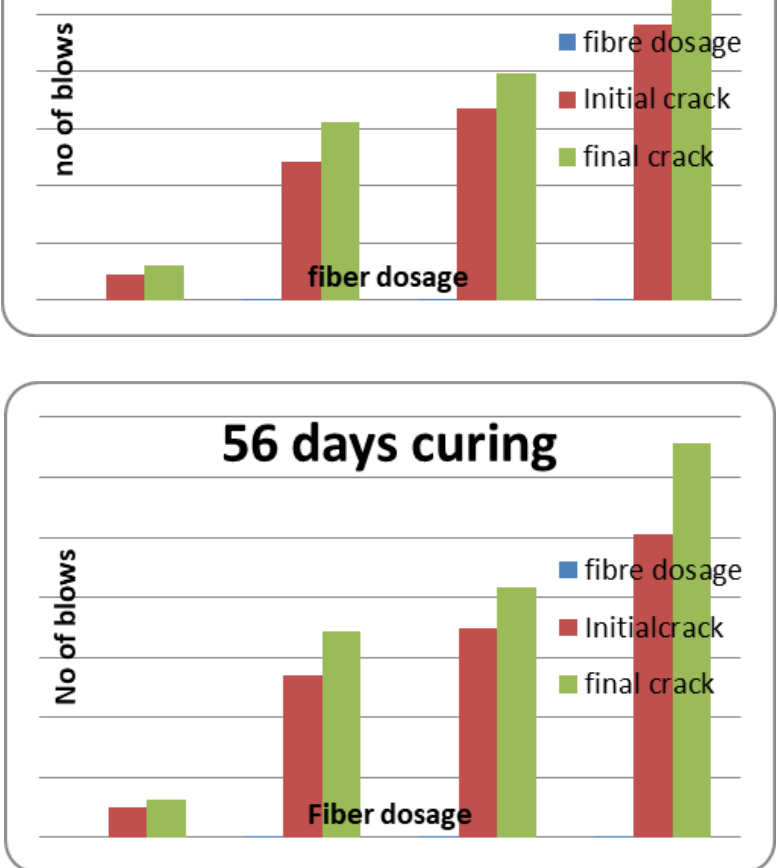

Fig 5 : No. of initial and final blows different Steel fibre dosages

\section{8 days curing}
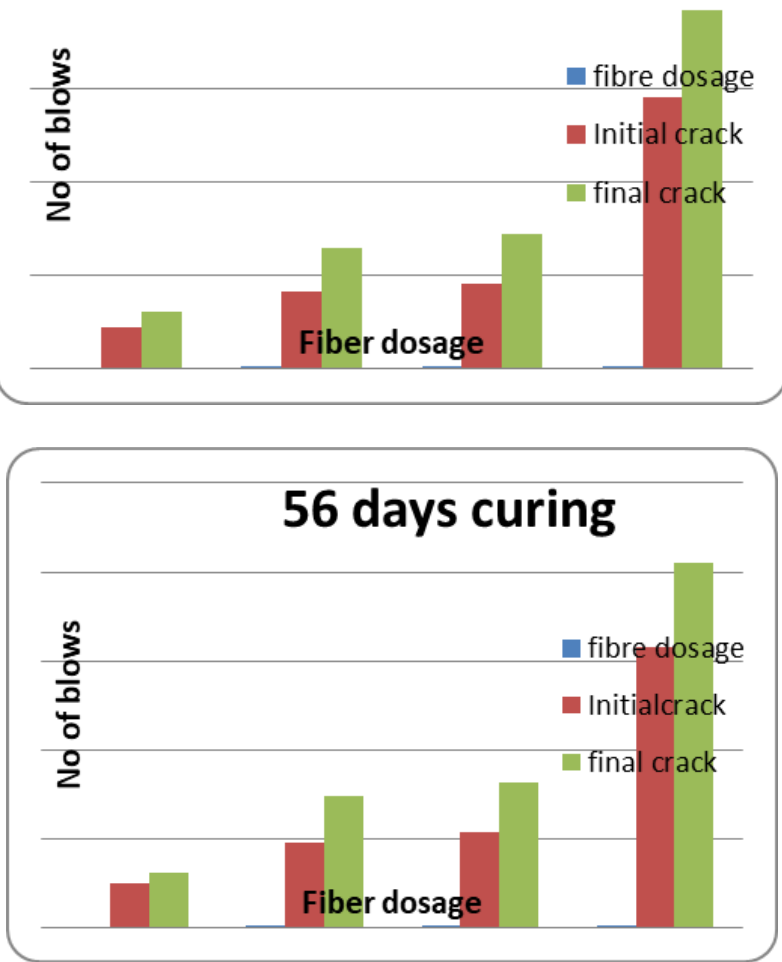

Fig 6 : No. of initial and final blows with different Polypropylene fibre dosages

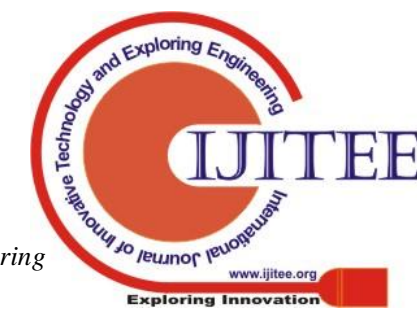



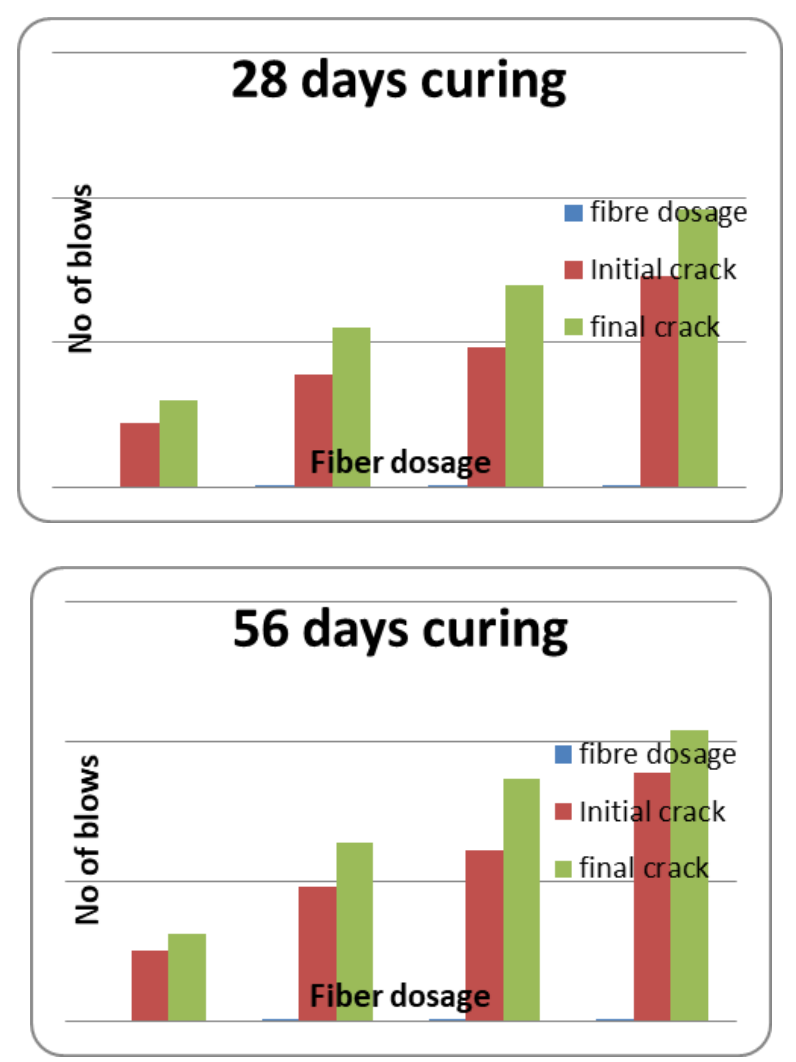

Fig 7: No. of initial and final blows with different Sisal fibre dosage

From the results it is settled that the effect hindrance of fiber fortified bond have ended up being higher than that of customary concrete as showed in Figs 5-7. unmistakably wire of strands (metallic, polypropylene, sisal) improved the impact resistance of bond. it's far said that effect block of metal fiber sustained strong end up being higher than that of polypropylene and sisal fiber strengthened concrete. it is in like manner raised that polypropylene fribre strengthened concrete accomplished high effect block than sisal fiber fortified bond. The development in fiber estimations improved the effect hindrance of bond in light of impact inside the malleability of concrete.
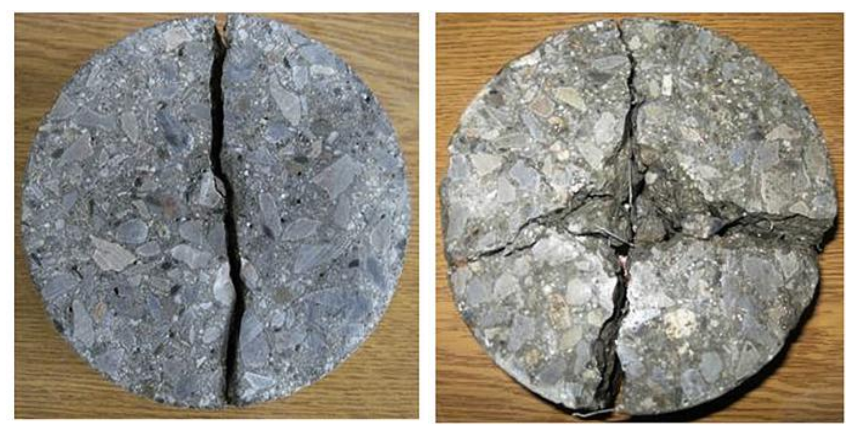

Fig.8 crack patterns (a) Plain concrete (b) Steel fibre reinforced concrete

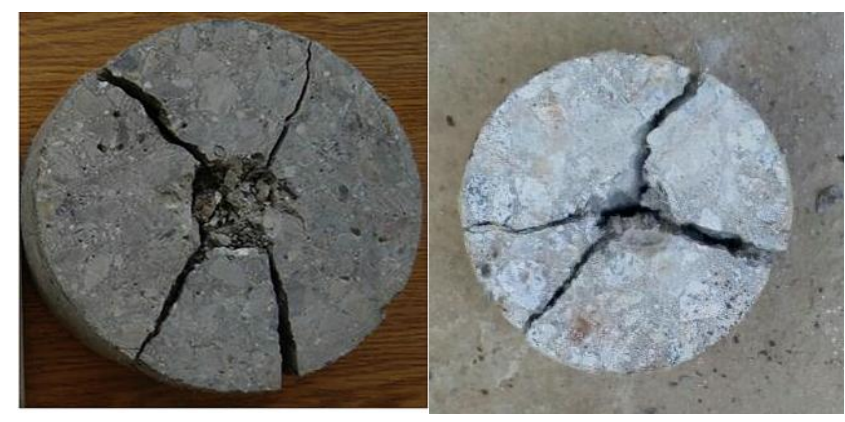

C) polypropylene FRC

D) Sisal FRC

\section{CONCLUSIONS}

In slight of the effects of this take a look at exam, the going with closures can be drawn:

1. The impact check of fiber braced concrete is better than that of everyday bond.

2. The effect resistance of metallic fiber bolstered concrete is higher than that of polypropylene and sisal fiber strengthened bond.

3. The augmentation in fiber element extended the effect check of concrete because of boom within the malleability of bond

\section{REFERENCES}

1. tune $\mathrm{P}, \mathrm{Wu} \mathrm{J}$ and Hwang $\mathrm{S}$, Assesment of actual collection as a end result deterrent of excessive-strength metallic Fibersustained Cocncrete,CemCmcr Res, 3512 (2005) 393-399

2. music $\mathrm{P}, \mathrm{Wu} \mathrm{J}$ and Hwang $\mathrm{S}$, Assesment of actual series as a give up end result deterrent and best reability of steelPolypropylene Hybrid Fiber-sustained Concrete, assemble and Bldgonater, 19 (2005), 1-nine.

3. ACI Commite 544.Measurment of residences of fiber reinfirced concrete. ACI Mater J 1988;eighty 5(6):583-90 3.

4. Marar adequate, Eren O, Celic T. Mater allow 2001;47:297e304.contemplated an affiliation between imapct imperativeness and compressive strength of immoderate caliber of fiber reinforcrd concrete.

5. Ramakrishnan v, Coyle WV, Kulandaisamy V, Schrader EK. ACI Mater J 1981; 78(5):388e94.

6. Nataraja MC, Dhang N, Gupta AP. Quantifiable assortments in reality deterrent of metallic fiber sustained concrete provided to drop-weight take a look at. Concrete Concr Res 1999;29(6):989-ninety five.

7. MohamoudniliV,Afroushabet be part of effect of silica smoke and metallic fibers of effect resistance and meachanical homes of bond Int J affect Engg,37 (2010) 879-886

8. Mohammadi Y, Carkon-Azad R and Singh S P,effect limit of metal robust bond containing fibers of combined factor of view ratio,assemble and Bldg Mater, 23 (2009) 183-189

9. Chen Xiang-yu,Ding Yi-hing and AZenedo C, solidified impact of steel strands and steel rebars on effect take a look at of first magnificence concrete,JCntrl South UnivTechnol, 18(2011) 1677-1684

10. AtefB,Ashraf $F$ and Andrew ok, Stastical assortments of impact block of Polypropylene Fiber-strengthened Concrete,Int J have an effect on Engg,32 (2006) 1907-1920 